\title{
Power Electronics for a 1-Kilowatt Arcjet Thruster
}

Robert P. Gruber

Lewis Research Center

Cleveland, Ohio

\section{LBBAARY BOPY}

sep 8 glo

LANGLEY RESEAACH CENTER

LIBRARY, NASA'

YAM:MTON, YIRGIHIA

Prepared for the

22nd Joint Propulsion Conference

cosponsored by the AIAA, ASME, SAE, and ASEE

Huntsville, Alabama, June 16-18, 1986

\section{N/SA}


31176013240990 


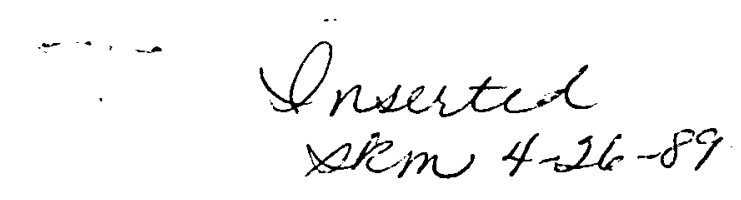

ERRATA

NASA Technical Memorandum 87340

(AIAA-86-1507)

POWER ELECTRONICS FOR A 1-KILOWATT ARCJET THRUSTER

Robert P. Gruber

June 7986

Page 1, column 2, paragraph 2: Line 1 should read, "For a $1 \mathrm{~kW}$ thruster similar to the thruster discussed".

Page 7, column 1, last paragraph, third sentence: Delete Initial.

TABLE - MAGNETIC COMPONENTS: Core 55128-7F should be 52128-1F; Core 55106-1D should be 52106-10.

Figure 1: All dots should be on the left side of the windings.

Figures 5, 6, and 9: Flow rates should be in SCCM.

Figures 7 and 8: Flow rates should be in SLM.

* Figure Bl: All dots on $L_{1}$ should be on left side of windings. 


\title{
POWER ELECTRONICS FOR A 1-KILOWATT ARCJET THRUSTER
}

\author{
Robert P. Gruber \\ National Aeronautics and Space Administration \\ Lewis Research Center \\ Cleveland, Ohio 44135
}

\section{Abstract}

After more than two decades, new space mission requirements have revived interest in arcjet systems. This paper reports the preliminary development and demonstration of new, high efficiency, power electronic concepts for start up and steady state control of dc arcjets. The design comprises a pulse width modulated power converter which is closed loop configured to give fast current control. An inductor, in series with the arcjet, serves the dual role of providing instantaneous current control, as well as a high voltage arc ignition pulse. Benchmark efficiency, transient response, regulation, and ripple data are presented. Tests with arcjets demonstrate that the power electronics breadboard can start thrusters consistently with no apparent damage and transfer reliably to the nondestructive high voltage arc mode in less than a second.

\section{Nomenclature}

e

i

R

$R_{n}$

$R p$ and the arc discharge voltage at a given current, $V$

\section{Introduction}

During the 1960 's, considerable effort was expended by both the industrial and government sectors on arcjet thruster research and technology. A comprehensive survey made in 1965 documented and summarized the state-of-the-art at that time.

Arcjets ranging in power from 1 to $200 \mathrm{~kW}$ were investigated. It was found that current limited power was needed for stable operation of the arc due to negative slope of the arc voltage versus current characteristic in the region of operation. Limited work was done with high efficiency, lightweight flight type power electronics circuits for arcjets although laboratory power supplies and special regulators ${ }^{2}$ necessary for arcjei operation and characterization were available. Typically, resistor ballasted power supplies were used.

Work in the 60's was temporarily abandoned due to lack of sufficient space electric power and near term mission applications. New space mission requirements have revived interest in the arcjet.3-8 As a thruster concept, it has the potential of high thrust and power densities, simplicity, and choices of propellants to suit specific impulse and system requirements. In addition, the evolution of power electronics technology over the last two decades provides new circuit technology and components that can now be used to advantage in arcjet systems.

\section{SIMILAR TO THE THRUSTER}

For a $1 \mathrm{~kW}$ sito thrusteradiscussed in this report, a feasibility demonstration of flight type power electronics circuits is reported in a 1963 article. 9 The breadboard circuits described used a magnetic amplifier to establish an open loop constant current power source for the arcjet thruster. Component limitations at that time resulted in a nominal operating frequency of $2 \mathrm{kHz}$. Power efficiency was 85 percent. No starting circuits were described. Starting was accomplished by either mechanically touching, then separating, the electrodes or by inducing a breakdown with a charged capacitor. During the time since this work was done, new components and circuit techniques became available enabling higher efficiencies as well as higher frequency operation with promise of reduced weight.

Arcjet thrusters have unique and not well understood power electronic requirements for starting as well as stable steady state operation. For spacecraft, arcjet power electronics should also have high power efficiency, lightweight, high reliability, simplicity, modest cost, and conform to typical spacecraft electrical specifications.

From a spacecraft thruster system standpoint it is important to avoid imposing overconservative thruster requirements on the power electronics. Tolerances specified on current regulation, response time, and ripple can impact power electronics weight, power, efficiency, cost, and parts count. However without test data, thruster tolerance to power electronics limitations is difficult to determine. For these reasons, it was chosen to develop and test basic flight type circuits with the thrusters even though the thrusters are continuously being modified to operate at different voltage, currents, and power levels. In addition, starting requirements are in the process of being defined. This development philosophy allows the power electronics designer the opportunity to help determine requirements and optimize system characteristics to assure a thruster system of most benefit to potential users.

The approach taken for this work uses the circuits designed for the thruster as a tool to determine suitable thruster-power electronics specifications. As part of this effort some new techniques for starting and powering an arcjet were demonstrated.

This paper describes the preliminary design and demonstration of a closed loop controlled high efficiency constant current source with an integral 
automatic starting circuit. The design comprises a high frequency PWM (pulse width modulated) power converter closed loop configured to give fast response output current control. An inductor in series with the load provides instantaneous current control, an ignition pulse, and an isolated signal proportional to arc voltage. The fast response control loop, in conjunction with the inductor, results in instant arc current.control. The isolated voltage signal proportional to arc voltage was used to demonstrate a new optional control mode. Benchmark data for the power system operating into a resistive load are presented, thruster simulator, thruster steady state and startup tests are discussed.

\section{Requirements}

\section{Thruster System Considerations}

Work done in the 1960's provides limited basic information regarding thruster system power electronic requirements. Very little information exists that describes the dynamic and static power supply characteristics that would best start, operate, and stabilize an arcjet. Furthermore, dc arcjet tolerance to spacecraft type power supply parameters such as high frequency ripple, closed loop control dynamics, and stored energy were not fully investigated.

The work described in this paper addresses some of these system requirements and resolves some of the power electronics-thruster issues.

A system development option was chosen for this work that tested the spacecraft type power electronic circuits with the thruster early in the program, before either was mature. As expected, this resulted in an iterative process towards obtaining information necessary for developing a flight thrustor system. One advantage of early integration is that major power electronic-thruster compatibility issues are addressed before extensive development of either the power electronics or the thruster is undertaken. Otherwise, development effort for either the power supply or the thruster will be at risk should integration problems arise. other important advantages for developing the power electronics along with the thruster are the elimination of overconservative tolerances for power electronic specifications and the promise of optimum thruster/power supply system characteristics. Experience with ion thruster power supplies shows that relaxing certain power electronic requirements markedly reduces system complexity and can substanstantially lower system cost. IO The impact of specifications on typical power processors are also treated elsewhere. 11

The breadboard spacecraft type power circuits that are being used in this development are expected to require revisions as more is learned about the arcjet system. Since the circuit is still a changing development tool, weight and performance will not be optimized until requirements are firm. Furthermore, it was judged that detailed examination of component stress levels under temperature extremes and transient conditions should also be postponed.

The power electronics must perform several functions to assure reliable, high performance thruster system operation. The thruster system should start and transfer to steady state in a reliable, repeatable manner that does not damage the thruster or limit useful lifetime. This could possibly involve control of propellant chamber pressure as well as thruster power electronics. In addition, startup and transfer to steady state should be rapid to prevent propellant loss. During steady state operation, arc voltage and current should be controlled to be within the limits necessary for thruster system performance needed for a particular mission. For certain missions it may also be necessary to throttle arc power and (or) propellant flow rates.

The thruster system should be protected against potentially damaging transient conditions such as loss of propellant pressure and low mode operation that could occur either accidentally during preflight system testing or during flight.

\section{Thruster}

Arc thruster volt-ampere characteristics over a practical operating range exhibit a decrease in voltage with increasing current or a negative resistance slope. Operation over a given voltampere curve is subject to disturbances in the changing location of the arc, gas flow, electrode erosion, and thruster and propellant temperature. It has been observed for certain thrusters, that changes in the operating mode from high to low voltage can spontaneously occur at constant arc current 5 and that operation in the higher voltage mode is best for thruster iife and performance. 12 Preliminary data show that using a constant current source is a viable way to operate an arcjet. Dynamic as well as static constant current is needed. However, other combinations of dynamic and static power supply characteristics have been implemented for this initial effort to determine the best way to start, operate, and stabilize an arcjet. Conditions for arc stability with a power source are discussed in the literature 13 for voltage sources with a pure resistance (ballasted supply) in series with the arc and for other power sources where the output voltage decreased as a nonlinear function of increasing output current. 14 Essentially the negative slope of the ballasted supply or nonlinear power source must have a more negative slope than the arc characteristic in the neighborhood of the operating point. The criterion for stability may be stated mathematically as

$$
\frac{d e}{d i}-R_{n}>0
$$

For a ballasted supply $R_{n}$ is equal to minus R. Qualitatively, the greater the value of the ballast resistor or negative power source slope in the region of the operating point, the more stable the operating point. This stability criterion is for one particular arcjet characteristic curve. For some thrusters operating from a constant current source the thruster characteristic curve has occasionally spontaneously changed to another curve. Large changes (e.g., from 100 to $50 \mathrm{~V}$ at $10 \mathrm{~A}$ ) are mode changes and small changes (within $10 \mathrm{~V})$ have appeared as voltage noise at constant current. These arcjet phenomena were observed with the PWM power supplies. Occasional slight voltage increases for certain thrusters during normal constant current operation requires power electronics capability to momentarily supply 10 to 20 percent more power than nominal operating power. 
Otherwise the current will reduce and the arc can extinguish. Possible mode change to low voltage mode requires thruster protection that will be discussed later.

Using closed loop control techniques, a power circuit can be created that appears as a voltage source in series with a negative resistance. The power source has a positive slope in the region of the operating point. The stability theory developed in the literature is not general enough to be used in this new special case, so the theory is extended in Appendix A. Mathematically the stability criterion is

$$
R p-\frac{d e}{d i}>0
$$

Inequality (Eq. (2)) is always satisfied for a positive slope power supply used with a negative slope arc characteristic. This is not true of inequality (Eq. (1)). Therefore inequality (Eq. (2)) suggests that a positive slope output power source may be advantageous for ensuring stability, particularly when the arc negative slope is very steep. The influence of a positive slope power source characteristic on possible mode shifts in certain thrusters or small arc characteristic changes has not yet been evaluated.

The stability criteria just described do not take into account the transient response characteristics of the thruster or the dynamic characteristics of the closed loop controlled power source. Dynamic characteristics of dc arcs for small sinusoidal ac currents superimposed on the dc operatjing points are discussed in the literature. 3,14 at low frequencies, the arc dynamic characteristics coincide with the arc static characteristic. At high frequencies, the small signal arc volt ampere characteristic is essentially the same as for a pure resistance. At high frequencies, the rate of change of ionization is relatively slow and does not change appreciably in a cycle. So the arc voltage increases with current as it would in a resistance. Because of its inherent negative slope for frequencies below where the slope becomes positive, the thruster could become part of an oscillator circuit under certain conditions. This is particularly true if the stray capacitance across the thruster hecomes significantly large.

Thruster frequency response has not yet been fully determined. Thruster tests described later for $13 \mathrm{kHz}, 1.5 \mathrm{~A}$ average to peak cyclic current variations superimposed on the $10 \mathrm{~A}$ thruster operating current show that the dynamic thruster characteristic still has a negative slope. This is a relatively fast response since carbon arcs in air are reported to have a positive slope for frequencies on the order of $1 \mathrm{kHz} .13$

Power electronic design options must be compatible with fast thruster response. For this initial development, it would have been useful if the dynamic and static power source characteristics were identical with response times faster than the thruster. This was not practical for the circuits chosen except for the constant load current design option. To prevent thruster damage, thruster transient voltage and current levels and duration must be limited under all possible thruster conditions for any design option chosen.
As a preliminary specification for the constant current power supply load dynamic characteristic, it was judged that closed loop response time for a step change in load should be less than $500 \mu \mathrm{s}$. It was also judged that the magnitude of the current change for a step change in load resistance of two to one should be less than $3 \mathrm{~A}$ for a $10 \mathrm{~A}$ load. In addition, of course, the power electronics closed loop control system should not be de-stabilized by the negative slope characteristic of the thruster.

For the circuits chosen to implement the power supply positive slope characteristic in the region of thruster operation, fast current change is not possible. Therefore, as a trial for the first tests, current response to voltage changes were chosen to be on the order of $2 \mathrm{~ms}$.

Certain functions can be incorporated into the power electronics for thruster protection. Destructive low mode operation can occur spontaneously in some thrusters or under conditions of accidental low pressure operation. Arc voltage can be sensed and used to detect low mode operation. Low mode detection can then initiate corrective action. Corrective measures could include delayed shutdown and recycle, changing the power electronics output characteristics, actuating gas pressure or gas mixture control valves or even adjusting thruster electrode spacing if absolutely necessary for long term missions.

The thruster must tolerate a certain amount of high frequency ripple for the flight type circuit design option used in this work. It was judged that up to 15 percent average to peak current ripple with a fundamental frequency of 10 to $20 \mathrm{kHz}$ would have no adverse effect on thruster life and performance.

A means must be provided to start the arcjet. There are several different methods. Some of the methods could be used in compination. (1) Mechanical schemes have been used where the electrodes are momentarily forced to touch. (2) A method where gas composition is temporarify changed can start the thruster. (3) A technique can be used where the discharge is initiated using radio frequency energy. 15 With that approach, radio frequency chokes are used to isolate the power source from the thruster. (4) Another method reduces propellant gas pressure until a discharge is initiated; then the pressure increased. (5) 0ther techniques start a discharge by raising the electrode voltage instead of lowering the propellant pressure. The high voltage source could either be a separate power supply used in conjunction with a high voltage blocking diode ${ }^{6}$ or a pulse generator.

For this work it was judged that thruster mechanical schemes were complicated and would take too long to implement. Reducing propellant gas pressure until a start occurs and then increasing the operating pressure can result in destructive low mode startup for some thrusters. In addition, possibly destructive high voltage glow discharges can occur. Momentarily changing gas composition requires mechanical valves and was judged complex at this time. Radio frequency startup has the advantage of initiating breakdowns at voltages lower than the static breakdown voltage. However, this method was also judged to be too complex at this time. Raising the thruster electrode voltage 
to initiate a discharge was chosen for this work. Raising the thruster static voltage requires either a very large power supply or a separate high voltage power source used in conjunction with a high voltage blocking diode. The diode adds about $10 \mathrm{~W}$ per junction power dissipation to the thruster system. Pulse starting requires a voltage slightly higher than static voltage breakdown, but eliminates the need for a blocking diode and separate power source. New pulse starting techniques can also utilize components already necessary for steady state operation. Therefore pulse starting (surge breakdown) was chosen instead of static voltage starting.

Surqe breakdowns are discussed in the literature.13,16 For pulse voltages the breakdown voltage can be somewhat above the static breakdown voltage due to the finite time required to produce electrons and establish the cumulative ionization process. For pulse breakdowns, the difference between actual breakdown voltage and static breakdown voltage is designated overvoltage. Breakdown voltage depends upon gas pressure and type, electrode geometry and condition, voltage rise time, and pulse duration. For small spheres in air with a $5 \mathrm{~mm}$ gap, the time lag for 10 percent overvoltage was reported as 1.5 is. 16 There are some random variations in overvoltages and time lags but higher overvoltages generally result in shorter time lags. A long pulse voltage rise time will permit the thruster to start at lower overvoltages and will, therefore, ease insulator stress. Actual thruster breakdown characteristics compared to most breakdowns previously studied are complicated by vortex flow gas dynamics, complex electrode geometries and condition, and strong gas pressure gradients. Pulse characteristics desirable for reliable starting influence pulse transformer design. A long duration slowly rising high voltage pulse should produce reliable starting. However, requiring a duration longer than necessary can result in a larger pulse transformer. Therefore, it was judged that a pulse duration of 5 us would be adequate for the thrusters currently in use. The maximum pulse voltage requirements for reliable starting under all conditions has not yet been established. From experience higher voltages result in quicker, more reliable starting. To date peak pulse voltages of 700 and $1600 \mathrm{~V}$ have been used. A pulse repetition rate of about four pulses per second was chosen for convenience. Automatic pulser shutdown upon ignition and automatic pulse startup when the thruster extinguished was chosen as the first design option to be explored. The initial startup surge current and energy level must be limited to prevent possib.le thruster damage or reduced lifetime. Any high voltage transient that could occur during shutdown or interruption of propellant flow must be limited to avoid damage to the thruster internal insulator.

\section{Spacecraft Considerations}

The thruster power electronics should eventually have the properties typical of spacecraft requirements; high power efficiency, light weight, and high reliability. In addition, the spacecraft power bus must be electrically isolated from the thruster. This precludes the possibility that the thruster could arc to spacecraft ground. Destructive discharges to equipment inside the vacuum test facility have occurred when the thruster cathode was connected to facility ground. Spacecraft power bus EMI, transient, and audio susceptibility requirements are secondary considerations at this point in the development of arcjet power electronics. As these requirements are defined, they can be met using filters and shielding. It was also judged that high and low temperature operation, component stress levels, as well as gain-phase (Bode) plots to determine stability margins should be addressed later in the program when the thruster needs are better defined.

\section{Design}

\section{Design Philosophy}

The thruster power electronics breadboard is regarded as a flexible development tool used towards gathering information needed to develop a reliable spacecraft thruster system with clean power electronics. The breadboard is continuously undergoing modification as more is learned about the thruster-power supply interface and as thruster requirements and power levels change.

For this arc load application, a key consideration is that any energy stored in a capacitor that could not be isolated or quickly disconnected from the arc load is undesirable since the uncontrolled transient energy release could cause unnecessary electrode damage. With output filter capacitors this could occur even though static output current regulation is used. Furthermore, significant amounts of capacitance across the arc negative resistance characteristic can, under certain conditions, form an oscillator circuit. Therefore, the approach selected has no uncontrolled capacitor energy storage except for about $300 \mathrm{pF}$ presently found in the shielded cables connecting the power electronics to the thruster.

The basic power circuit chosen was an output current controlled PWM parallel converter capable of being optimized for high efficiency and lightweight. Many variations of the basic PWM power circuit have been used in spacecraft voltage regulators during the past quarter century. Some incorporate transformers to isolate the output. Direct current voltage from the spacecraft power bus is chopped at audio frequencies or higher. The ratio of on to off time of the semiconductor chopping switch is varied to control average voltage. A low pass inductor-capacitor filter smooths out the chopped voltage train to produce regulated dc output voltage. This regulation concept is simple in principle. However, weight and performance requirements, as well as circuit subtleties and unspecified component characteristics have historically made reliable custom designs difficult and expensive.

\section{Design Approach}

To create a controlled current source, the filter capacitor in the PWM voltage regulator $L-C$ low pass filter was eliminated and the inductor current was forced to be continuous. A transformer provided the necessary input-output isolation. The new design approach shown in Fig. 1 is a fast response constant current source with an integral automatic high voltage pulse starting circuit. The scheme comprises high frequency PWM parallel converter closed loop configured to give fast response current control. The commutated inductor in series with the arc load serves the three roles of providing ( 1 ) instantaneous current 
control, (2) a high voltage ignition pulse, and (3) an isolated signal proportional to arc voltage. Combining functions in the inductor saves using another heavy pulse transformer and separate signal isolation circuitry. The pulser also eliminates the blocking diode power dissipation and the need for the dc high voltage source used previously.

The ignition pulse is developed by charging the inductor from the current limited supply through a separate low voltage winding. When the current in the low voltage winding is interrupted (with a transistor switch) the inductor magnetic field collapses and a high voltage pulse is produced. The circuit initiates the pulse about four times each second until arc current is detected and then the pulser is automatically turned off. One advantage of this method of ignition is that the maximum initial pulse current is limited to a pre-selected value so unnecessary electrode erosion is eliminated. For over-voltage protection, the inductor voltage is clamped to a pre-determined value using the low voltage winding. This prevents over-voltage if the thruster does not start and also limits voltage transients should the arc extinguish.

During the part of the cycle when the PWM converter output is zero, the commutated inductor delivers energy to the load. At this time, the arc load voltage appears across the inductor and commutating diode. A separate isolated Faraday shielded winding and small diode are used to develop a signal proportional to arc voltage. This signal can be used to perform any number of functions. It could be used to detect low mode and to provide arc voltage telemetry. It was used in conjunction with the control system to provide a positive slope output characteristic in the region of thruster operation. As the output voltage increases so does the output current demanded from the controller. If necessary, more exotic static and dynamic output characteristic tailoring can be realized by replacing the adjustable gain arc voltage amplifier with active filters and function generators. The feedback signal could then make the output characteristic a variety of functions of arc voltage, current, and time.

From a controls standpoint, a dominant transfer function in a PWM control loop designed for voltage regulation is the second order transfer function introduced by the L-C filter. However, for current control the capacitor is left out and only a first order transfer function is introduced. Furthermore, this first order function fortunately integrates the effects of arc load voltage changes. Current cannot change instantiy for step voltage changes so the rest of the PWM control loop has time to adjust. The effect of the arc dynamic negative slope characteristic on the control system transfer function is also minimized by the inductor and large apparent resistance presented by the PWM controller.

Design Growth Potential

The PWM current regulated converter has potential for higher power. For high voltage ( $>100 \mathrm{~V}$ ) spacecraft buses, a bridge converter instead of the parallel converter used for this work would better utilize semiconductor switch capabilities and result in a simpler and lighter power transformer. However, switch drive and isolation requirements lead to a more complex power circuit. PWM power capability is primarily limited by the semiconductor switches used. In addition, spacecraft component derating reliability policies prohibits using full semiconductor switch capability. These policies are somewhat subjective and can vary markedly between organizations. Todays power MOSFETS have limited power capability but can be used in parallel. At some power level the number of parallel devices becomes cumbersome. It is judged that single power stage PWM current regulation designs using todays MOSFETS can be practical to about $10 \mathrm{~kW}$. It is also judged that practical single stage PWM circuits for power levels to about $50 \mathrm{~kW}$ can be achieved using single bipolar transistors (e.g., D7ST) as switches. Bipolar transistors are much more difficult to use in parallel than power MOSFETS. For power levels on the order of $50 \mathrm{~kW}$ and higher, switching devices such as silicon controlied rectifiers (thyristors) could be considered, but turn off circuits are complex and power circuit concepts other than PWM control may be more competitive. Since it is current regulated, the PWM power stage should be easy to use in parallel combinations to achieve redundancy as well as high power.

It is judged that power efficiencies near 95 percent can be achieved for arcjet voltages greater than $100 \mathrm{~V}$ using a PWM current regulator.

Power electronics weight is influenced by spacecraft bus voltage specifications. The need to regulate against wide bus voltage variations, will result in heavier magnetic components and capacitors. Furthermore, stringent conducted EMI and audio susceptibility requirements will increase input filter weight. It is judged that a $1 \mathrm{~kW}$ PWM arcjet power supply meeting spacecraft vibration, EMI and thermal specifications would weight about $4 \mathrm{~kg}$.

Power supply parts count for $1 \mathrm{~kW}$ thruster spacecraft power electronic system is judged to be nearly 100 components at this time.

\section{Design Details}

Since the first tests with an arcjet, the power electronic circuit design is still in a state of transition together with the thruster. Circuit requirements and details have changed, but the concepts and approach described earlier have not. The circuit details are presented in Appendix B. For the tests recorded in this paper, the pulser was modified to provide a slow rate of rise. The $1 \mu \mathrm{F}$ capacitor that clamps the pulser output voltage was not connected to the input voltage through a $100 \Omega$ resistor as shown. Instead, the capacitor was discharged to ground through a $27 \mathrm{~K}$ resistor. This had no significant effect on the current regulator steady state characteristics and transient response.

Tests

\section{Resistive Load Tests}

Resistive load tests were performed to establish benchmark load and line current regulation, load transient response (stability), ripple, power efficiency, and pulser performance. Circuit performance under temperature extremes and measurement 
of component stress levels under transient condi$t$ ions should also be examined when all the thruster requirements are identified and the power electronics design is closer to being finalized.

Regulation. Power supply static resistive load characteristics are plotted in Fig. 2 . The current control was set for about $10 \mathrm{~A}$ at $100 \mathrm{~V}$ since this was the setting used for the thruster tests described later. To establish line regulation, data were taken at 100 and $120 \mathrm{~V}$ input to the power electronics breadboard. Current and voltage ripple were averaged with filters. Only $120 \mathrm{~V}$ input was used for thruster tests. One set of curves defined current control and the other set of curves described an optional current and arc voltage control to produce a positive slope power supply characteristic.

The current control provides constant current in the region of thruster steady state operation. Higher currents at lower voltages were permitted for the circuit used here so that the response time could be easily made as fast as practicable. The short circuit current (not shown) was $18 \mathrm{~A}$. If necessary, this current increase at low output voltage could be minimized and response time retained by modifying the current sense and control circuit. On the other hand, this characteristic may be beneficial for reliable damage free arc starting. Further tests with other load profiles are needed to establish this because the high current surge may be a real requirement. If so final power electronics weight will be higher. The positive slope control data were taken at the settings used for thruster and thruster simulator. tests.

Transient response. Fast dynamic response to load changes was judged a key control loop requirement for the development of arcjet power electronics. Fast response raises the concern of control loop instability. The speed achieved may be faster than necessary since speed may be traded for other performance parameters. Figure 3 shows power supply transient responses for constant current control. Fast step resistive load changes from 10 to $4.8 \Omega$ and from 4.8 to $10 \Omega$ were introduced using a solid state switch. The current disturbances were small except for the slight current drop transient just after a step change in load from 4.8 to $10 \Omega$. This was not seen in previous versions of the circuit and is believed to be a result of the pulser $1 \mu F$ capacitor clamp being tied to ground through a $27 \mathrm{~K}$ resistor instead of being tied to the input voltage through a $100 \Omega$ resistor. The capacitor needs a one time charge when the inductor voltage increases for the large step load transient. This variation of the circuit was used for all the tests described in this report. For this circuit variation, the pulser had the advantage of a slower rate of rise starting from low voltage.

The step response shows that the system was stable with a resistive load. Spontaneous step thruster changes also verified stability. However, a gain/phase (Bode) plot with an arc load or arc load simulator would need to be done to identify any possible conditional stability. (Control instabilities that will occur when the loop gain is decreased or increased.) If conditional stability exists, the circuit will perform well until some load or internal condition, such as amplifier saturation, changes the loop gain. The arcjet system has not yet been tested for conditional stability.

Ripple. Current ripple for this version of the circuit can be seen in Fig.3. Ripple at the nominal thruster operating point of $10 \mathrm{~A}$ and $100 \mathrm{~V}$ is about $1.5 \mathrm{~A}$ average to peak at $13.3 \mathrm{kHz}$. Ripple could be reduced if necessary by increasing the frequency or the averaging inductance.

Power efficiency. Power efficiency at $100 \mathrm{~V}$ and $10 \mathrm{~A}$ with $120 \mathrm{~V}$ input measured 91 percent. It is judged that the power efficiency of this scheme could be increased to near 95 percent by reducing magnetic component copper losses, paralleling power MOSFETS, and reducing switching losses. Increasing efficiency would markedly influence variations in efficiency with load power and input and output voltage. Therefore, these data were not presented since they could show misleading trends.

The pulser output voltage is shown in Fig. 4 . This was measured open circuit with shielded leads connecting the power electronics to the thruster. The lead capacitance measured $300 \mathrm{pF}$. The pulse represents the circuit variation where the pulser primary is clamped to a $1 \mu \mathrm{F}$ capacitor that is returned to ground through a $27 \mathrm{~K}$ resistor. Current instantly available at ignition depends upon maximum pulser switch current (adjusted by on time) and the voltage where the arc initiates. Available current for this circuit variation was not measured, but was initially about $6 \mathrm{~A}$ and decreased to zero when the pulse voltage reached $1.6 \mathrm{kV}$.

Weight. Breadboard component weight for the $1 \mathrm{~kW}$ arcjet power electronics was approximately $2 \mathrm{~kg}$. Component weight is expected to be reduced when the circuit is optimized. Most of the weight is the magnetic components which will decrease with optimization.

\section{Thruster Tests}

Thruster startup and steady state tests were performed with a recent design radiation cooled arcjef, with fully tangential propellant injection. 17 Cathode tip, chamber and nozzle half angles were $30^{\circ}$. The constrictor length and diameter were both $0.64 \mathrm{~mm}$. The anode cathode gap was set at $0.51 \mathrm{~mm}$.

Thruster starting tests. Starting thruster voltage and current transients were recorded with an oscilloscope camera and stripchart recorder. The oscilloscope was triggered using the power MOSFET gate signal that initiates the pulser operating sequence. This allowed observation of the beginning of the startup transients. A differential voltage measurement had to be used to isolate the instrumentation grounds from the thruster. Since the voltage probe impedances are not well matched at high frequencies, there are probably some artifacts above $200 \mathrm{kHz}$ in the voltage measurements. However, the current was measured using a magnetically coupled current sensor with a 0 to $50 \mathrm{mHz}$ bandwidth.

The initial tests used gas mixture ratios of 2:1 and $3: 1 \mathrm{H}_{2}$ to $\mathrm{N}_{2}$ to simulate hydrazine and ammonia propellant decomposition products. The thruster started at relatively low voltages 
$(<200 \mathrm{~V})$. Furthermore the thruster always started on the first pulse independent of initial chamber pressure for the first group of nine starts. Figures 5 and 6 show typical starts for two different flow rates and initial chamber pressures. The thruster reaches the nondestructive mode in a fraction of a second. Apparently at higher initial chamber pressures less time is spent in the transition from low to high mode. Comparison of starts in Figs. 5 and 6 show that the start at 39 psia initial chamber pressure reached high mode faster than the start at 28 psia. For starts at 17.75 psia initial chamber pressure the time in low mode was about $10 \mathrm{sec}$. High pressure starts consistently reached high mode faster. The startup and transfer to high mode was repeatable for all $n$ ine starts. The current surge for both starts began near $5 \mathrm{~A}$ and rose to about $17 \mathrm{~A}$ peak. The initial surge was over in about $2 \mathrm{msec}$.

About $20 \mathrm{hr}$ later another group of starts was tried. The thruster started reliably and transferred to the nondamaging high mode under a large $r$ ange of conditions. However, sometimes several pulses were generated before a start would occur. No oscilloscope data were available for these starts. It is assumed that a higher voltage or more energy may be needed for starts on the first pulse after initial thruster operation. The reasons for the low voltage starting in the initial tests may have to do with assembly cleanliness since this was the first time the thruster was re-run after being assembled. Figure 7 shows a sequence of three starts out of five at initial chamber pressures of about 28 psia. Startup was reliable, repeatable and transfer to the high voltage, nondestructive mode occurred within a fraction of a second.

Thruster steady state operation. Thruster steady state oscilloscope data are shown in Fig. 8 and strip chart steady state data can be seen in Figs. 5 to 7 . Power electronics operation appears as for a resistive load except for the arc ripple current and voltage which are $180^{\circ}$ out of phase. This shows that the thruster dynamic characteristic slope is still negative for the thruster beyond the $13.3 \mathrm{kHz}$ fundamental ripple frequency.

\section{Thruster Simulator Tests}

Startup and steady state tests were performed using a water cooled thruster simulator. ${ }^{6}$ For these tests the gap between the anode and cathode was $0.66 \mathrm{~mm}$, constrictor length was $1.14 \mathrm{~mm}$ and diameter was $0.64 \mathrm{~mm}$. Only fully tangential gas flow was used with a gas mixture ratio of $2: 1 \mathrm{H}_{2}$ to $\mathrm{N}_{2}$ which simulated hydrazine propellant decomposition products. Thruster simulator tests were performed using the same equipment and methods described for the thruster tests. The major objective of these tests was to evaluate and compare a positive slope power source characteristic with the constant current power source characteristic.

Figure 9 shows two typical thruster simulator startups and runs at steady state under different conditions. Figure $9(a)$ shows thruster simulator operation using the current control mode power supply characteristic given in Fig, 2 for $120 \mathrm{~V}$ input to the breadboard. Inttat eurrent in the region of thruster simulator operation is held constant even though the arc voltage varies about
$10 \mathrm{~V}$ peak to peak. The arc voltage noise is believed to be a thruster simulator phenomenon because the current remains regulated. The thruster simulator phenomenon is probably related to gap width. Figure 9(b) shows thruster simulator operation with the positive slope power source characteristic given in Fig. 2 for $120 \mathrm{~V}$ input to the breadboard. During startup the voltage as well as the current increase verifying positive slope operation. In addition, small voltage variations are accompanied by current noise. The positive slope current source compatibility with arc loads was demonstrated. 0ther tests with various slope values and arc conditions need to be tried to determine whether the positive slope power source technique is useful enough to justify the added circuit complexity.

\section{Conclusions}

The initial design and demonstration of new arcjet power electronics verifies that the fast response closed loop current control scheme can be used to reliably start and operate an arcjet. In addition, the design approach used is capable of producing high power efficiency and lightweight power electronics for the thruster system.

An integral high voltage pulse ignitor was demonstrated using the output current averaging inductor already necessary for the pulse width modulated power source. The charged inductor starting technique limits the maximum initial starting current to a pre-determined value and for that reason should result in longer thruster electrode life by preventing damage that occurs at startup in other starting schemes. In addition, a small winding on the inductor supplies a signal proportional to output voltage. Arc voltage is then used as a feedback signal to tailor power supply output static load characteristics. This new arc stabilization technique theoretically results in a more stable arc system which may be beneficial for certain arc characteristics typical of arcjets.

Thruster tests demonstrated that the power electronics can start certain thrusters consistently with no damage and transfer to the nondestructive high voltage arc mode in a fraction of a second.

\section{Acknowledgments}

The author wishes to acknowledge the technical assistance of Robert Gott in the design of the circuits and the help of Frank Curran and Shigeo Nakanishi during thruster and thruster simulator integration.

\section{Appendix A}

The purpose of this appendix is to develop a new stability criterion expression for positive slope power source characteristics when used with an arc load.

A stability criterion for arc-loads operating from negative s] ope power sources is described in the literature. 13 This criterion was developed by considering points where the power supply and arc characteristics intersect and then assuming that some transient condition increases or 
decreases current slightly. The current disturbance results in a small $\Delta e$ as shown at point $B$ in Fig. Al. For a negative slope power source characteristic, a positive $\Delta e$ increases current and a negative $\Delta e$ decreases current. An increasing current transient must reduce $\Delta e$ otherwise the current will be driven to a higher level. Likewise a decreasing current must increase $\Delta e$ or the current will continue to decrease. This can be stated mathematically as

$$
\frac{d(\Delta e)}{d i}<0
$$

from which the stability criterion is

$$
\frac{d e}{d i}-R_{n}>0
$$

Therefore, point $B$ is unstable. A negative power source steeper than the arc characteristic is needed for stability.

For a power source with a positive slope, the intersection with the arc characteristic is shown as point A, Fig. Al.

This power source has the property that a positive se tends to decrease current instead of increasing current. Conversely negative $\Delta \mathrm{e}$ effects an increase in current. Therefore, the condition for stability is reversed from Eq. (A1) or,

$$
\frac{d(\Delta e)}{d i}>0
$$

from which the stability criterion is

$$
R p-\frac{d e}{d j}>0
$$

$R p$ is already positive and de/di is negative for most practical arcs. Therefore, the inequality is always satisfied and the intersection of a positive slope power source characteristic and a negative slope arc characteristic should always be stable. This is not so for a negative slope power source intersection with the negative slope arc characteristic.

\section{Appendix B}

\section{Circuit Details}

The proof-of concept circuit schematic is shown in Fig. B1. The table describes magnetic component details. For convenience, some of the components were operated near maximum ratings. The choice of some of the parts was based on availability more than performance.

The pulse width modulation controller is integrated circuit UC 1846. The UC 1846 contains a reference voltage, error amplifier, oscillator, pulse by pulse current limiting, drivers, and all the basic functions necessary for pulse width modulation control. The UC 1846 drives a pair of power MOSFET transistors in a parallel converter. The MOSFET transistors are protected from voltage transients by snubbers and zener diodes. To protect MOSFET transistors from destructive currents, inductor $L_{2}$ limits current during $\mathrm{T}_{1}$ core saturation or during faults. $L_{2}$ is needed because on the order of $2 \mu \mathrm{s}$ elapse from the time overcurrent is detected until the power transistors can be turned off. The signal for current limiting protection is derived from a $0.05 \Omega$ shunt in the primary circuit. Arcjet current used for control is sensed using a current transformer, $\mathrm{T}_{2}$. Current transformer instead of shunt output current sensing is used to maintain input-output isolation. The current sensed by the current transformer was not continuous so it had to be either filtered or processed using a sample and hold circuit. For simplicity capacitor filtering was chosen. To maintain fast current response the capacitor was made as small as practicable. This resulted in higher static currents at output voltages well below the thruster operating voltage where the duty ratio is low. (See Fig. 2 Power supply static load characteristics.) To maintain closed loop stability for duty ratios above 50 percent a fixed ramp signal was added from the timing capacitor terminal 8 to the current sense terminal 4 of the UC 1846. The current signal needed for control is also used in conjunction with comparator LM311 to turn off or initiate the pulse start circuit. The inductor charging duration and duty ratio are established by the CD4098B, a dual one shot multivibrator. An IRF 350 transistor switches inductor, $L_{1}$ charging current on and off. When the IRF350 transistor turns off, the inductor voltage is clamped by a capacitance initially charged to the input voltage. During the pulse, the capacitor is charged further allowing the output pulse voltage to rise until the thruster discharge is established or until $L_{1}$ expends its energy. Then the capacitor discharges and is ready for the next pulse.

When $L_{1}$ is commutated and supplies energy to the arc, the inductor voltage equals the arc voltage plus a diode voltage drop (about $0.8 \mathrm{~V}$ ). A small shielded winding on $\mathrm{L}_{1}$ and a diode provide a signal proportioned to arc voltage. The signal is discontinuous. A series resistor limits current when the pulser is operating as well as forming part of an R-C filter used to smooth the discontinuous voltage signal. The voltage signal is used with a two transistor adjustable gain amplifier to provide optional output characteristic positive slope tailoring.

\section{REFERENCES}

1. Wallner, L.E.; and Czika, J., Jr.: Arcjet Thrustor for Space Propulsion. NASA TN D-2868, 1965.

2. Jenkins, R.C.; and Hoff, M.: Development of a Transistor Regulator System for Fine Current Control of an Arcjet. Grumman Aircraft Engineering Corp., RM-355, Feb. 1967.

3. Byers, D.C.: The NASA Electric Propulsion Program. International Electric Propulsion Conference, $17 \mathrm{th}$, Japan Society for Aeronautical and Space Sciences, Tokyo, 1984, pp. 1-9.

4. Stone, J.R.: NASA Electrothermal Auxiliary Propulsion Technology. AIAA Paper No. 86-1703, June 1986.

5. Nakanishi, S.: Experimental Performance of a 1-Kilowat Arcjet Thruster. NASA TM-87131, 1985. 
6. Curran, F.M.: An Experimental Study of Energy Loss Mechanisms and Efficiency Consideration in the Low Power DC Arcjet. AIAA Paper 85-2017, Sept. 1985.

7. Hardy, T.L.: Electrode Erosion in Arc Discharges at Atmospheric Pressure. AIAA Paper 85-2018, Sept. 1985.

8. Hardy, T.L.; and Curran, F.M.: Hollow Cathodes in High Pressure Arc Discharges. AIAA Paper 85-2035, Sept. 1985.

9. Boehme, R.J.; and Cagle, E.H.: Power Source for a 1-kw Arc Engine Test Capsule. AIAA J., vol. 1, no. 5, May 1963, pp. 1168-1169.

10. Gruber, R.P.: Simplification of Power Electronics for Ion Thruster Neutralizers. J. Spacecr. Rockets, vol. 21, no. 5, Sept.-0ct. 1984, pp. 473-480.

11. Biess, J.J.; and Schoenfeld, A.D.: Effect of Requirement Specification of Implementation of a Power Processor, 24th Power Sources Symposium, PSC Publications Committee, 1970, pp. $123-128$.
12. Curran, F.M.; and Nakanishi, S.: Low Power dc Arcjet Operation with Hydrogen/Nitrogen Propellant Mixtures. AIAA Paper 86-1505, June 1986 .

13. Cobine, J.D.: Gaseous Conductors. Dover Publications Inc., New York, 1958.

14. Buhler, R.D.; Moore, R.A.; and Stribling, R.E.: Power Conversion and Conditioning for 300-1200 KW Plasma Propulsion Systems. AIAA Paper 64-679, Sept. 1964.

15. Richter, R.: Investigation of Electrical Systems of Plasma Arc Jet Engines. AIAA Paper 63044-63, Mar. 1963.

16. Meek, J.M.; and Craggs, J.D.: Electrical Breakdown of Gases. Clarendon Press, London, England, 1953.

17. Curran, F.M.: Private Communication, NASA Lewis Research Center, Cleveland, $\mathrm{OH}$, April 1986. 
TABLE - MAGNETIC COMPONENTS

\begin{tabular}{|c|c|c|c|}
\hline & Device & Core & Windings \\
\hline & Power transformer & $\begin{array}{l}\text { One 55128-1F Mag. Inc. } \\
\text { and one A1185-H2EE GLS } \\
\text { Electronics- } \\
\text { cores stacked }\end{array}$ & $\begin{array}{l}\text { Primary: } 28 \text { turns number } 12 \text { AWG bifilar } \\
\text { Main secondary: } 36 \text { turns number } 12 \text { AWG } \\
\text { Pulser secondary: } 5 \text { turns number } 22 \text { AWG bifilar }\end{array}$ \\
\hline $\mathrm{T}_{2}$ & $\begin{array}{l}\text { Output current } \\
\text { transformer }\end{array}$ & $\underset{55106-10 \mathrm{Mag} . \text { Inc. }}{52106-10}$ & $\begin{array}{l}\text { Primary: } 1 \text { turn number } 12 \text { AWG } \\
\text { Secondary: } 600 \text { turns number } 30 \text { AWG }\end{array}$ \\
\hline $\mathrm{L}_{1}$ & $\begin{array}{l}\text { Output inductorl } \\
\text { pulse transformerl } \\
\text { arc voltage signal } \\
\text { transformer }\end{array}$ & $\begin{array}{l}\text { Three Al09156-2 Arnold } \\
\text { cores stacked }\end{array}$ & $\begin{array}{l}\text { Output winding: } 41 \text { turns number } 16 \text { AWG one } \\
\text { layer with gap between start and finish turns } \\
\text { Pulser primary: } 7 \text { turns number } 16 \text { AWG } \\
\text { Signal winding: } 4 \text { turns number } 22 \text { AWG shielded }\end{array}$ \\
\hline$L_{2}$ & $\begin{array}{l}\text { Transient current } \\
\text { limiting inductor }\end{array}$ & 55324-A2 & 6 turns number 16 AWG \\
\hline
\end{tabular}

$a_{1}$ and 2 mill cores of slightly different magnetic material were mixed for convenience. 


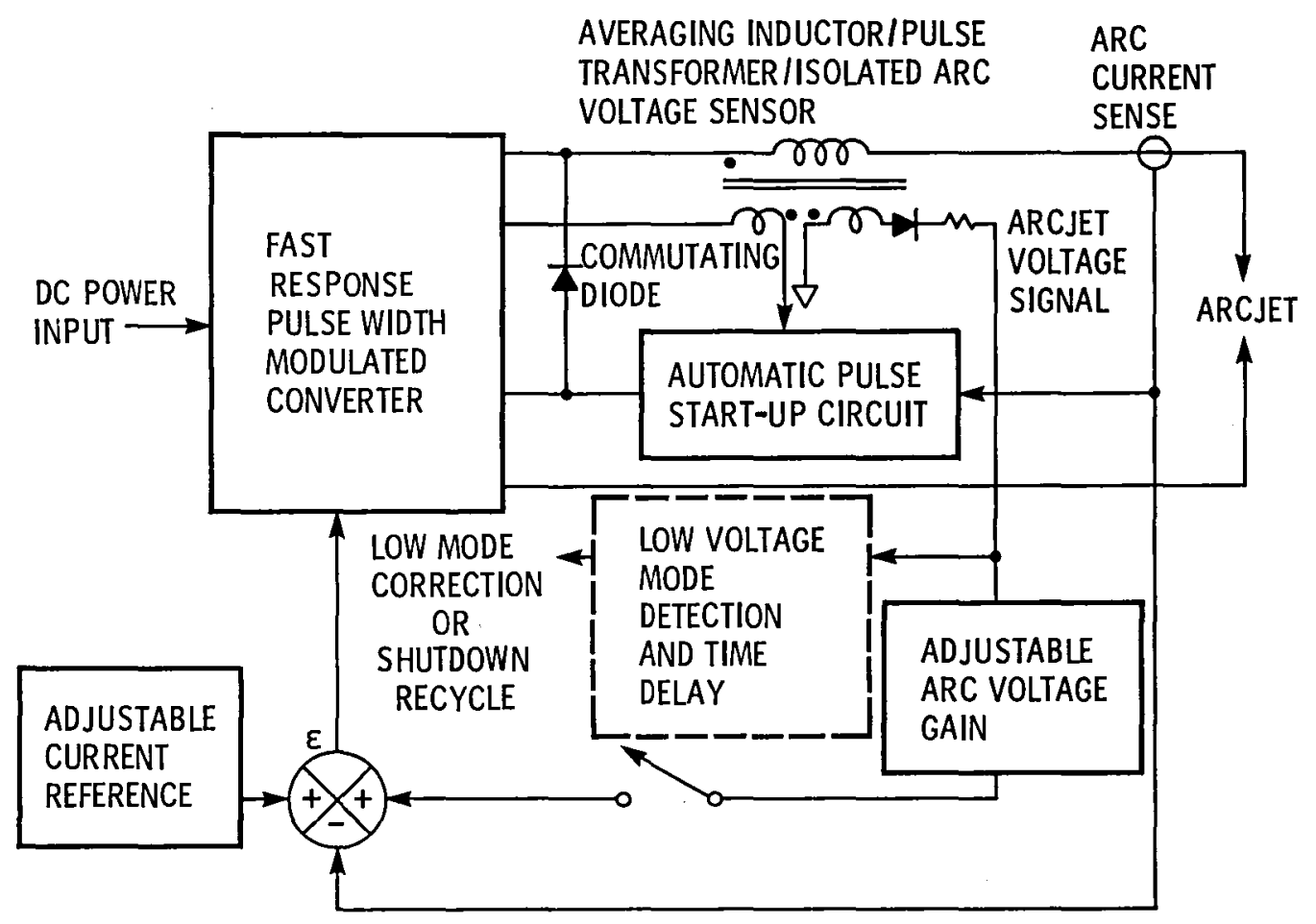

Figure 1. - Functional diagram arcjet power electronics. 


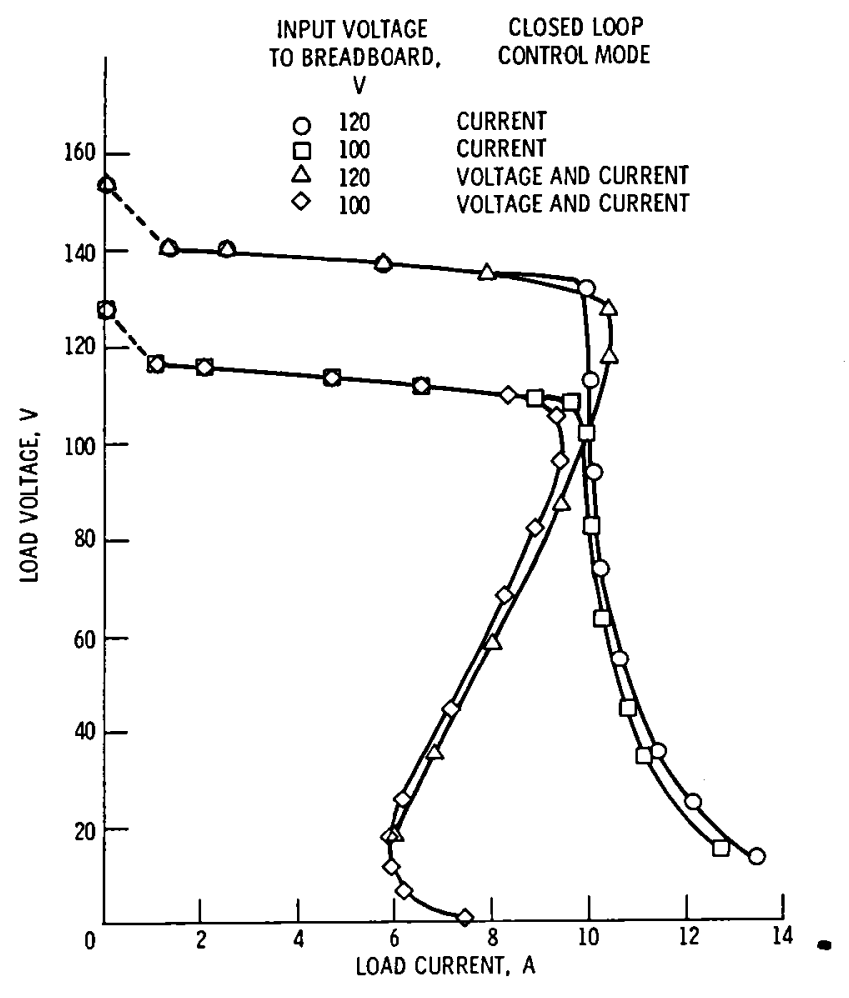

Figure 2. - Power supply static load characteristics. 


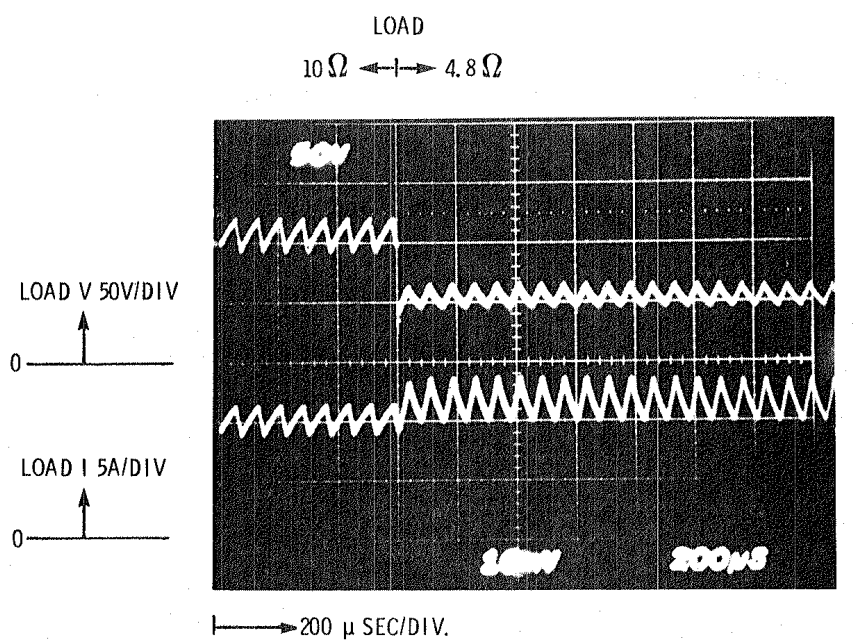

(a)

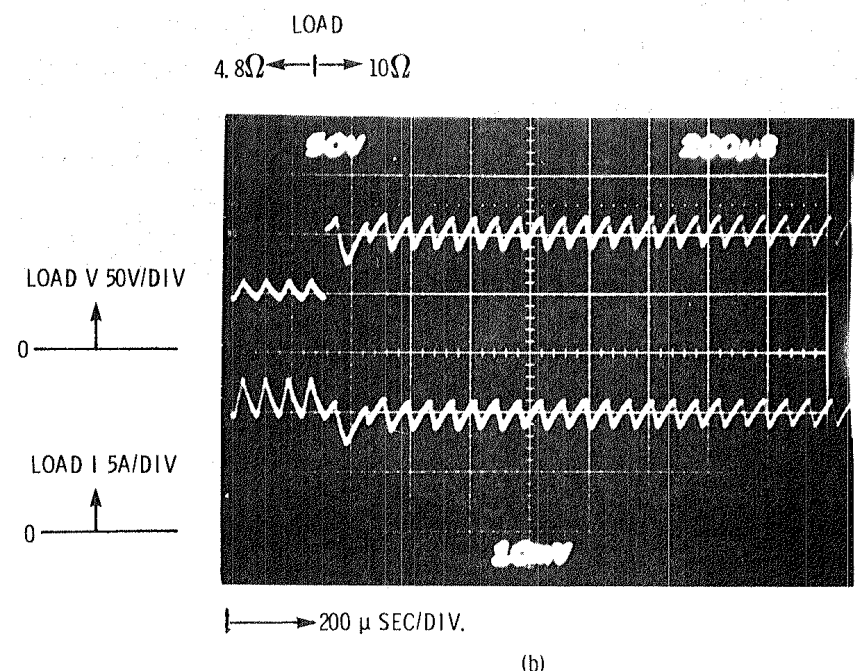

Figure 3. - Power supply transient responce and ripple with $120 \mathrm{~V}$ in for (a) step load change from 10 to $4.8 \Omega$, and (b) step load change from 4.8 to $10 \Omega$. 


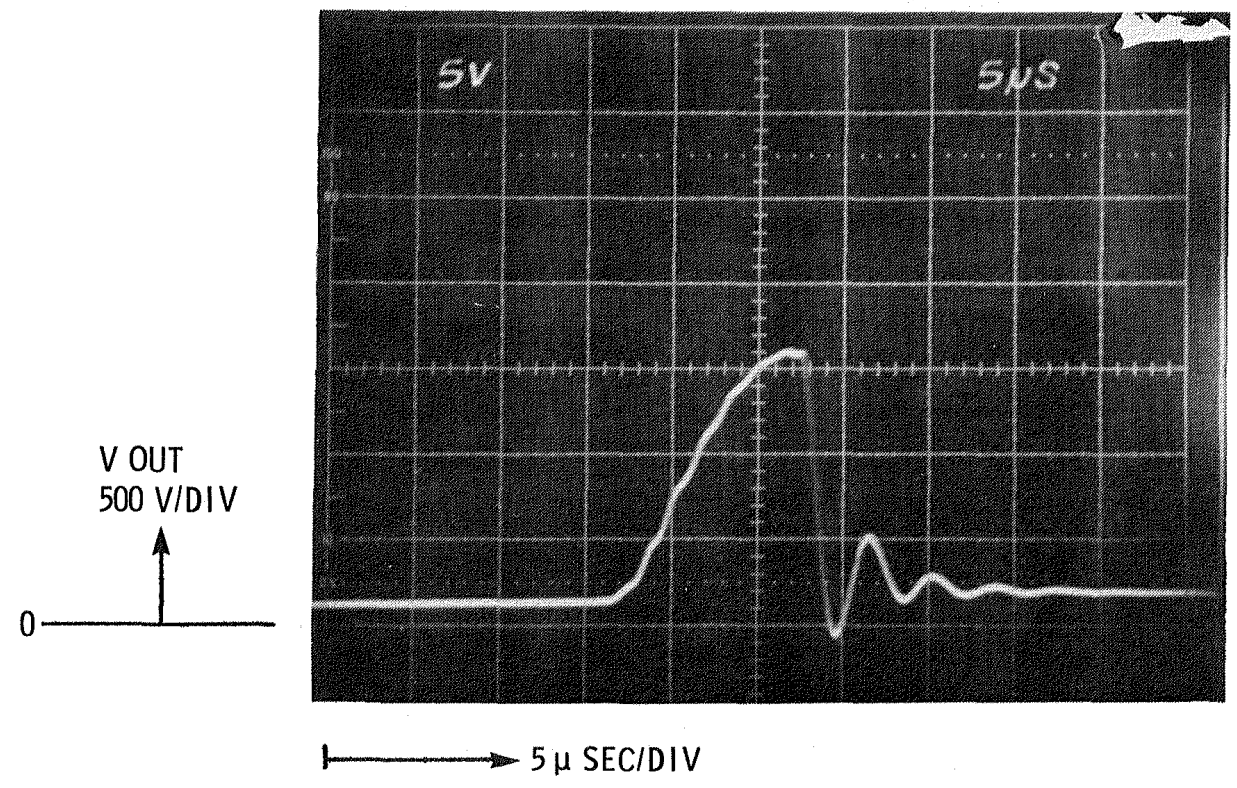

Figure 4. - Open circuit pulser voltage. 


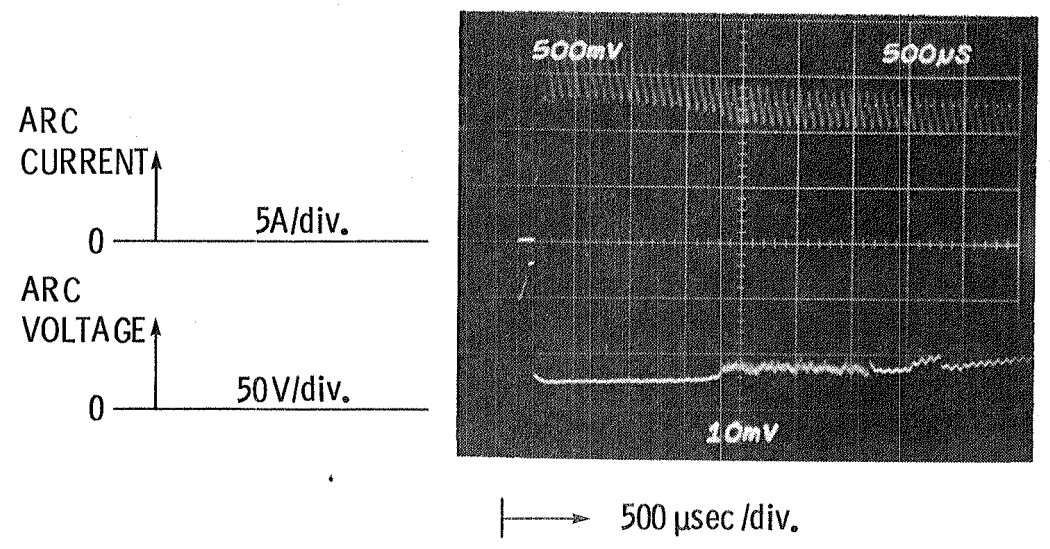

(a) Oscilloscope record.

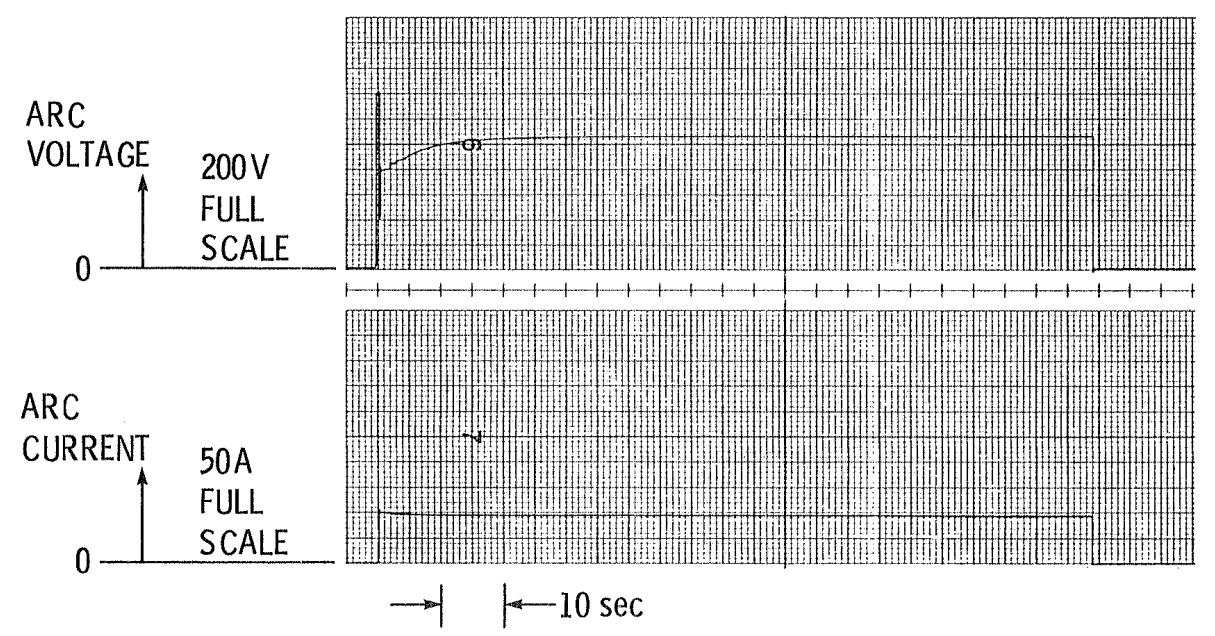

(b) Step chart record.

TEST CONDITIONS: INITIAL CHAMBER PRESSURE; 28.2 psia FLOW RATES: $\mathrm{H}_{2} ; 4500 \mathrm{SCCM}$ $\mathrm{N}_{2}: 1500$ SCCM

Figure 5. - Thruster startup voltage and current。 


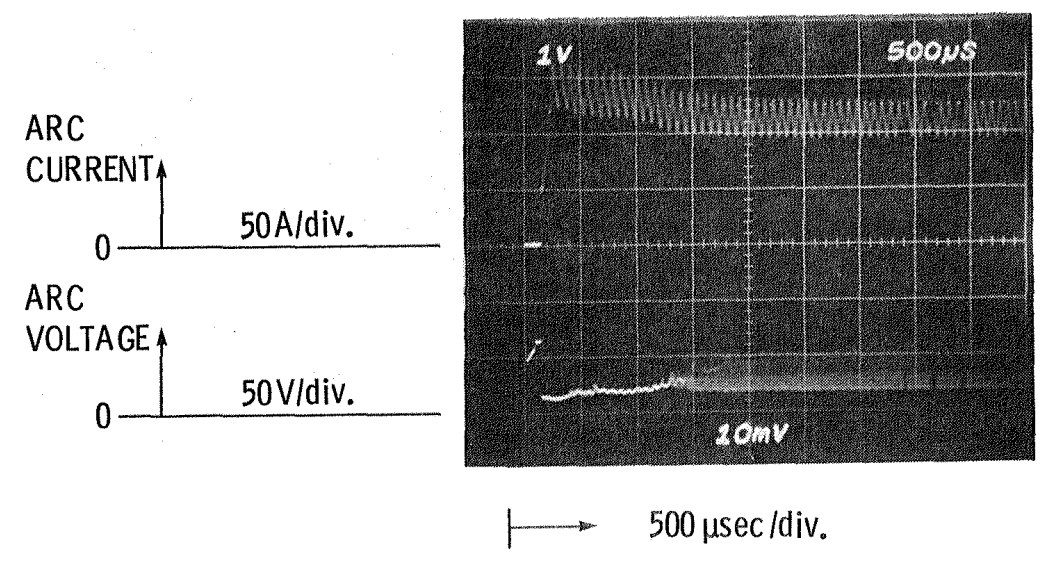

(a) Oscilloscope record.

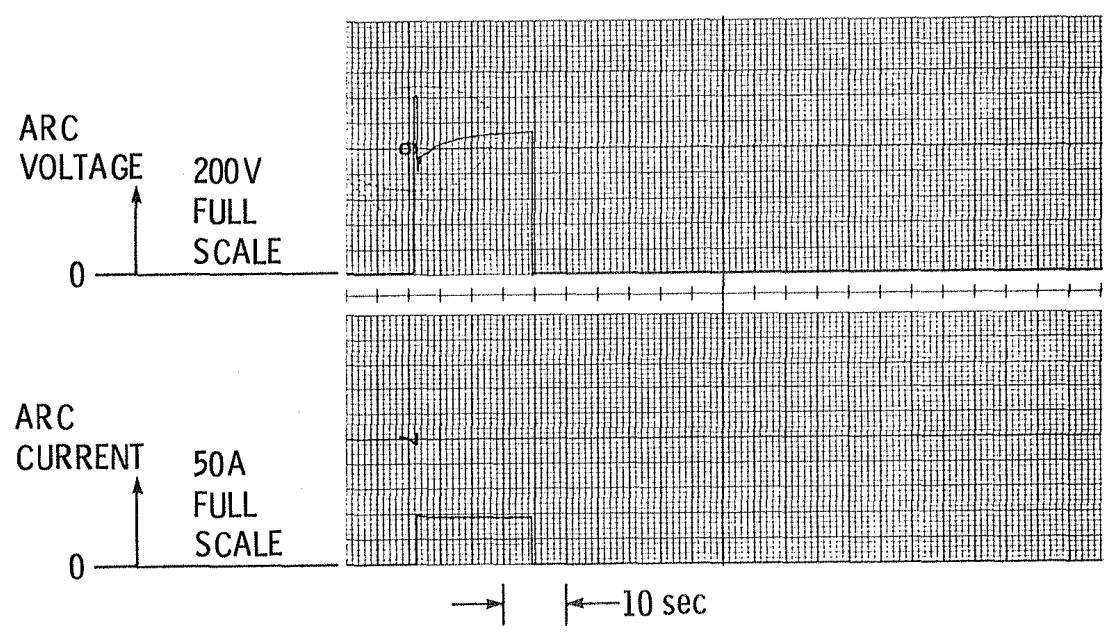

(b) Strip chart record.

TEST CONDITIONS: INITIAL CHAMBER PRESSURE; $39.0 \mathrm{psia}$ FLOW RATES: $\mathrm{H}_{2} ; 6020 \mathrm{SCCM}$ $\mathrm{N}_{2} ; 2020 \mathrm{SCCM}$

Figure 6. - Thruster startup voltage and current. 


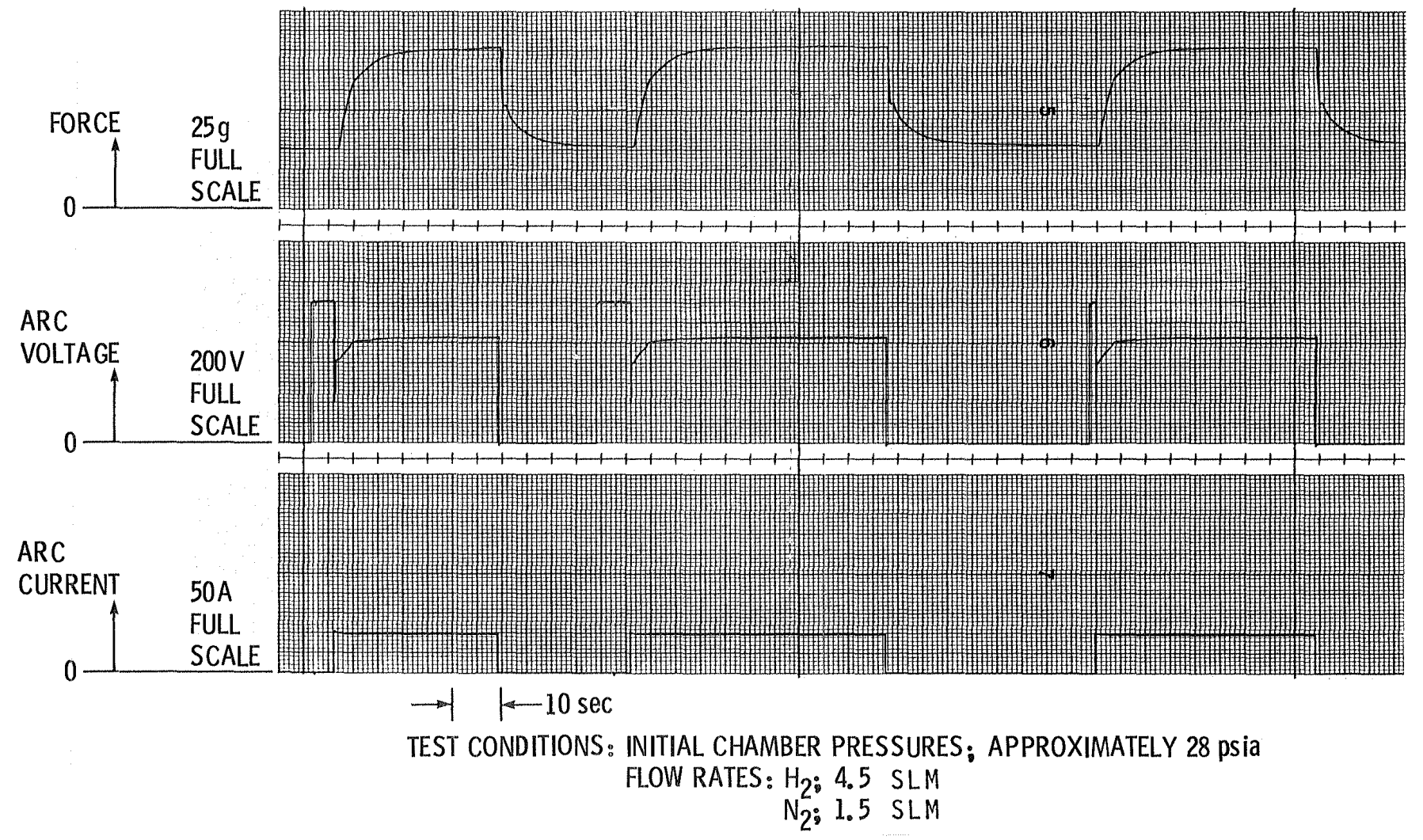

Figure 7. - Thruster starts。 


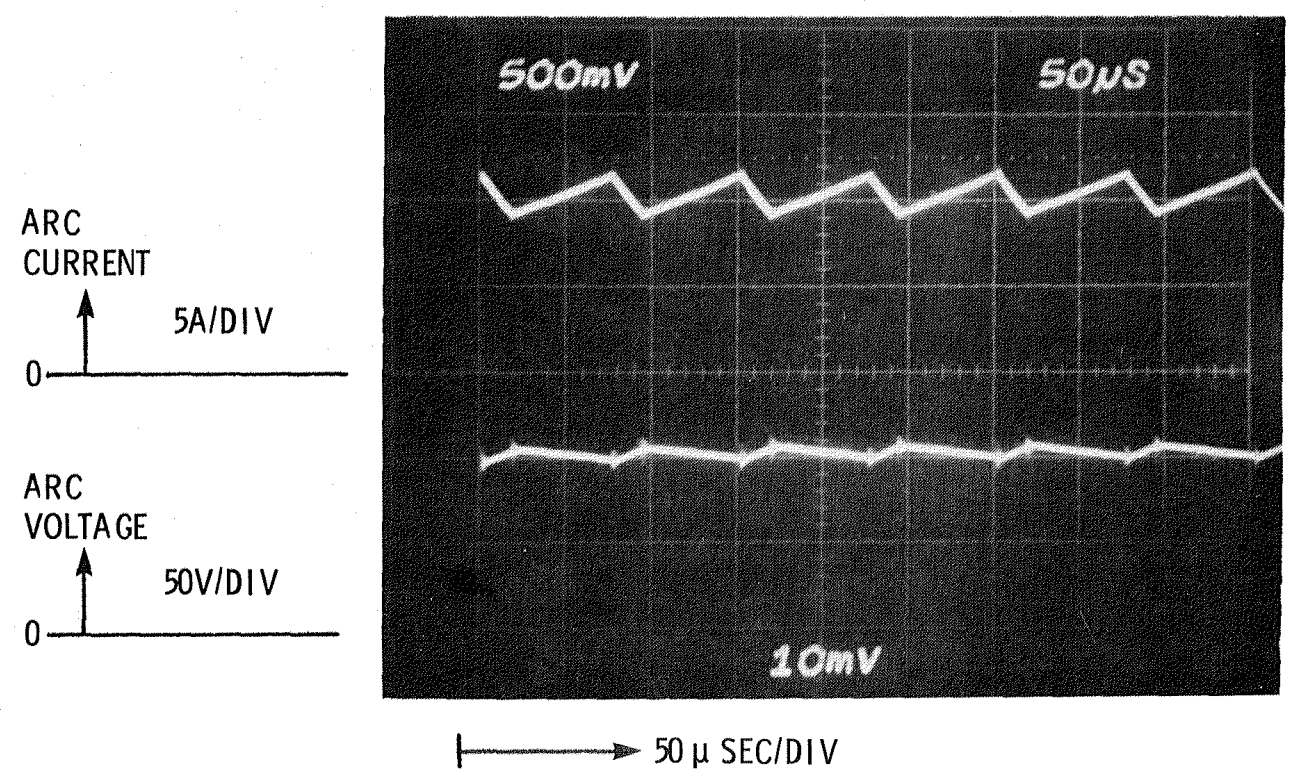

Test conditions: 1.5 SLM N

Figure 8. - Thruster steady state arc current and voltage. 


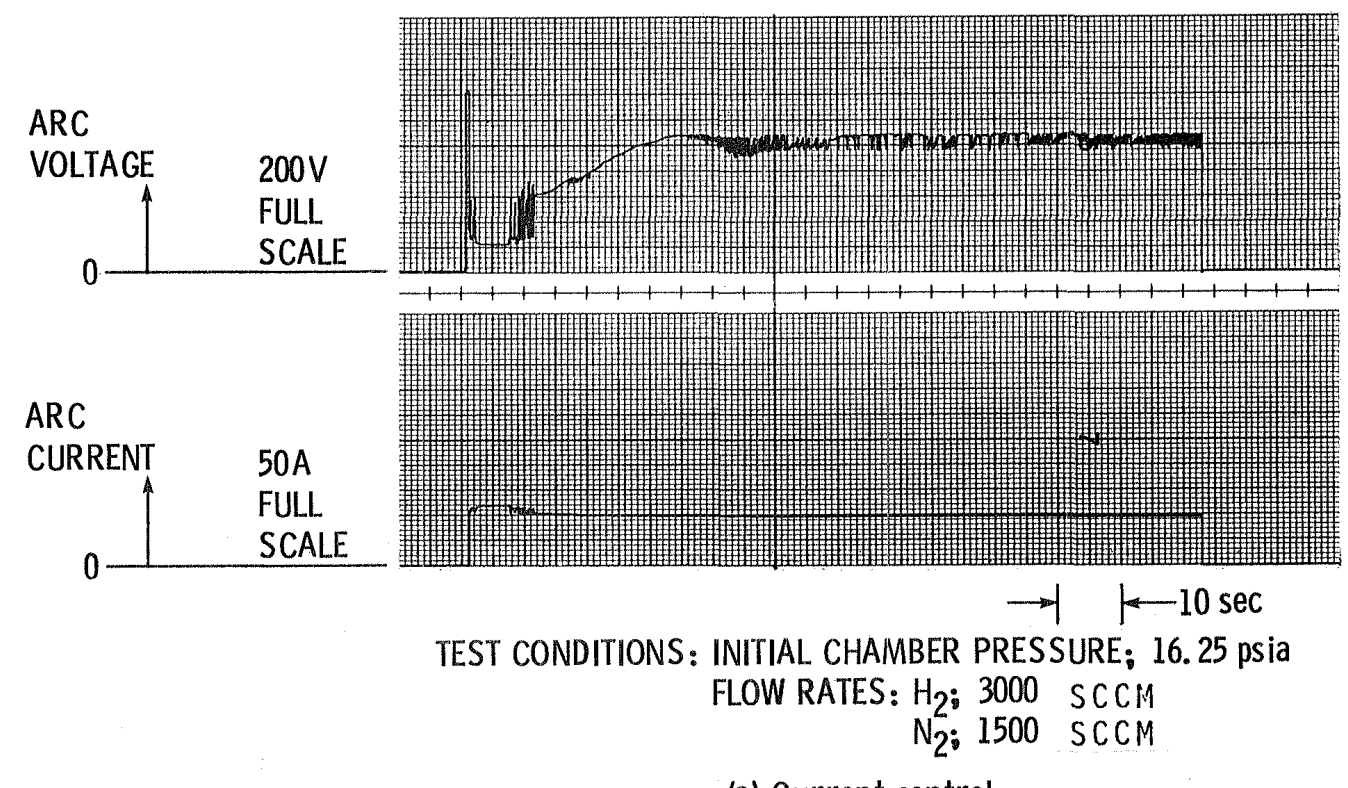

(a) Current control.

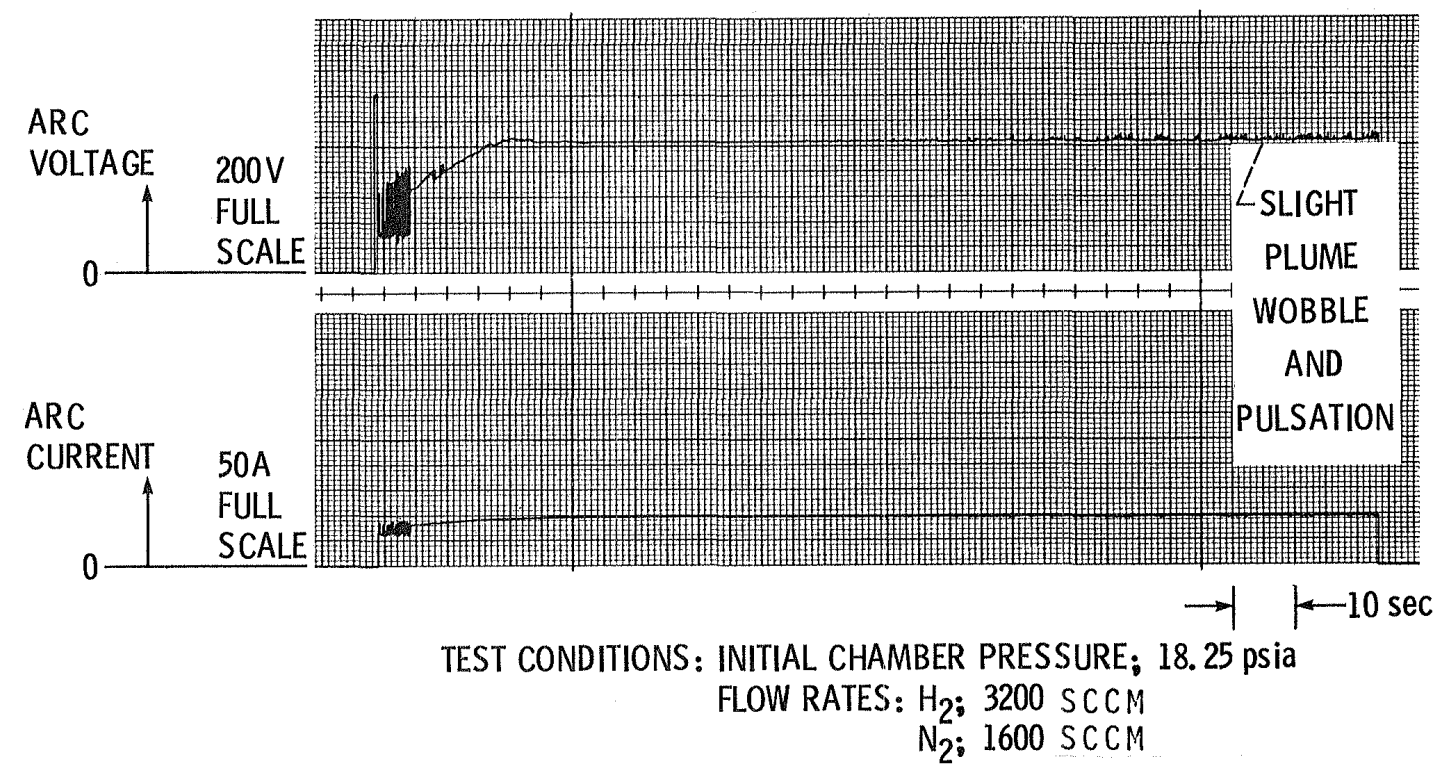

(b) Positive power source slope-voltage and current control.

Figure 9. - Thruster simulator tests. 


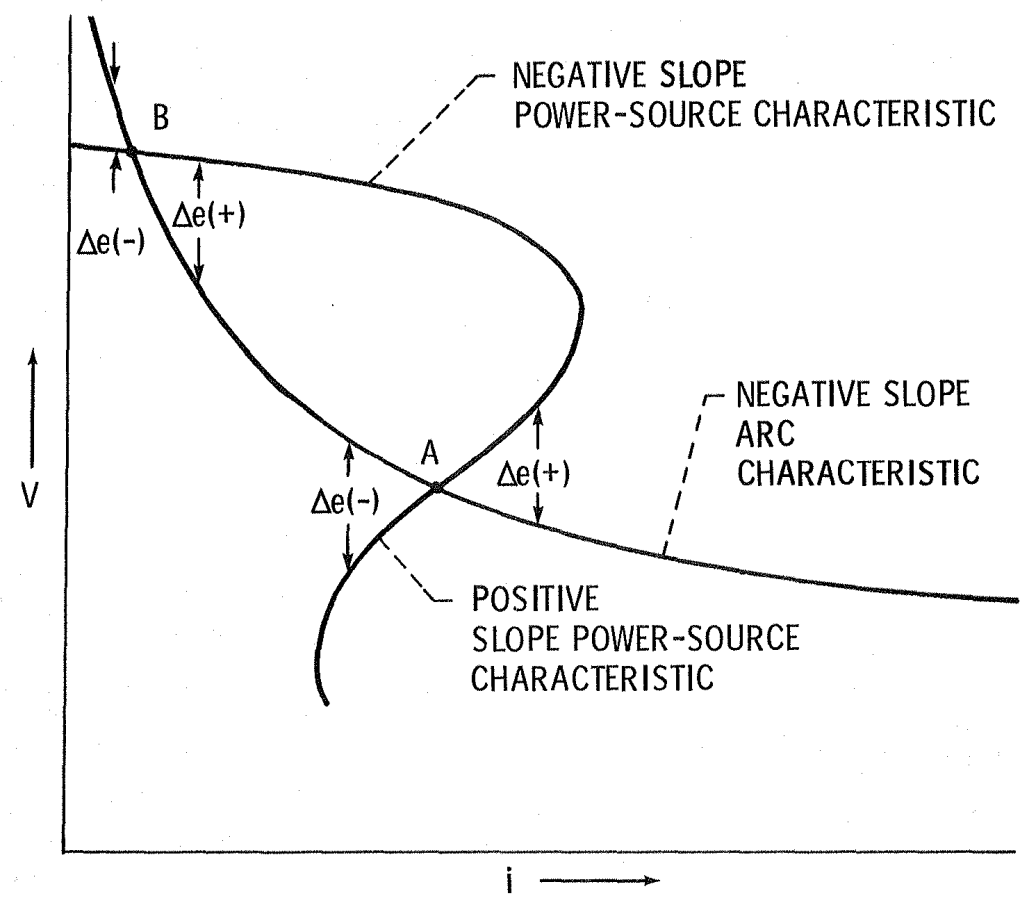

Figure Al. - Arc and power source characteristics. 


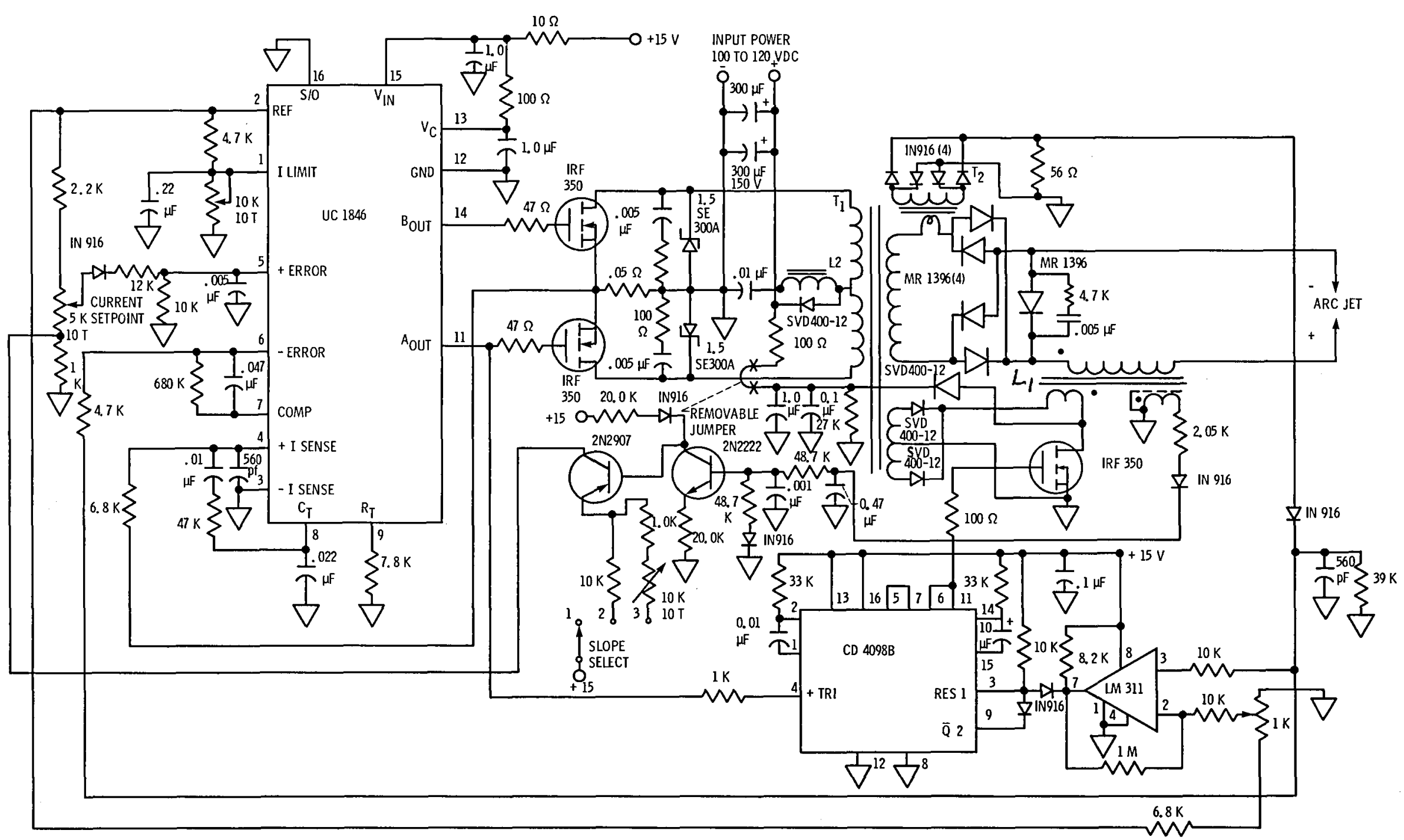

Figure BI. - Schematic arcjet power electronics proof-of-concept breadboard. 


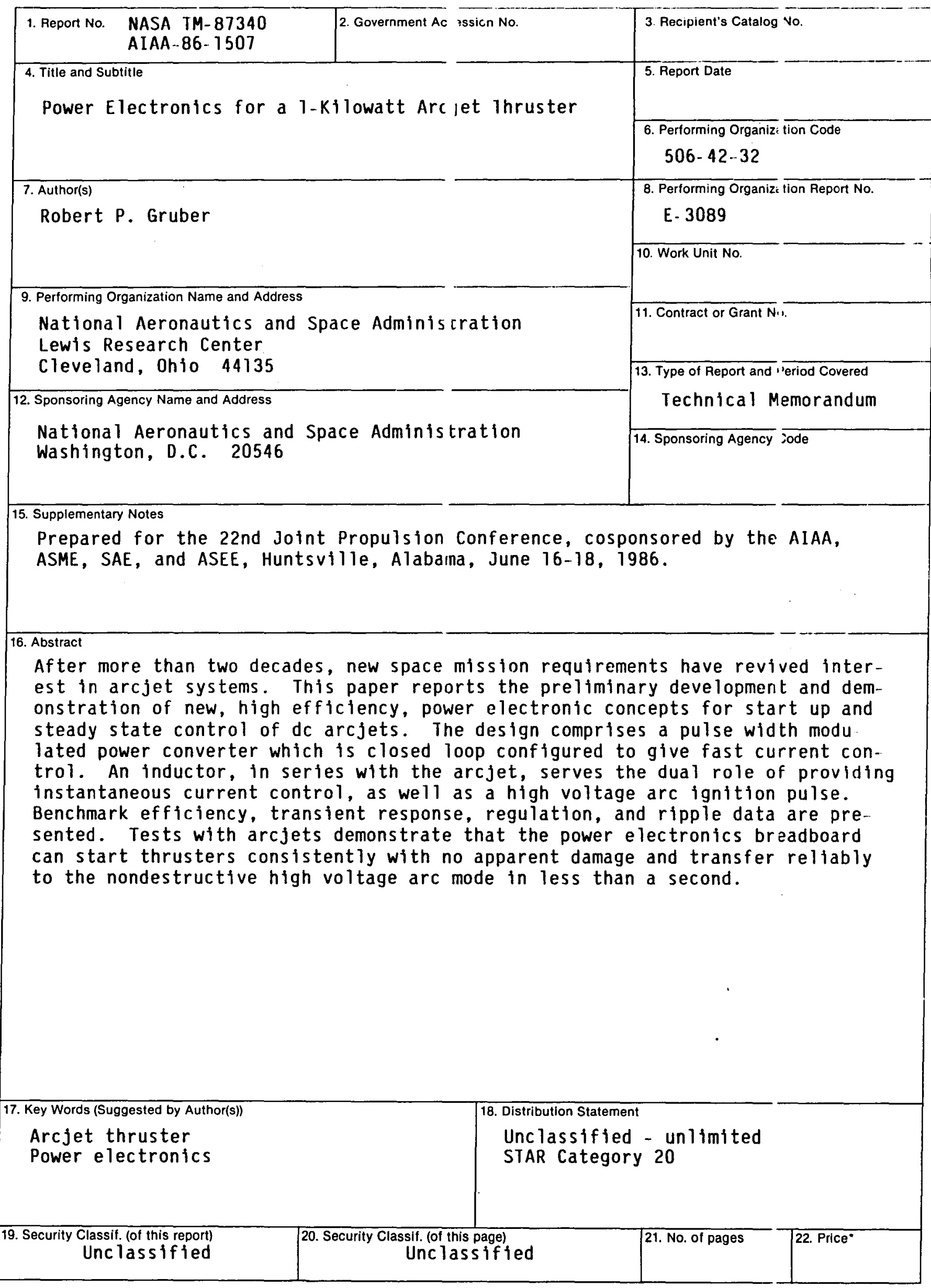




\title{
ERRATA
}

NASA Technical Memorandum 87340

(AIAA-86-7507)

\author{
POWER ELECTRONICS FOR A 1-KILOWATT ARCJET THRUSTER \\ Robert P. Gruber \\ June 1986
}

Page 1, column 2, paragraph 2: Line 1 should read, "For a $1 \mathrm{~kW}$ thruster similar to the thruster discussed".

Page 7, column 1, last paragraph, third sentence: Delete Initial.

TABLE - MAGNETIC COMPONENTS: Core 55128-1F should be 52128-1F; Core 55106-10 should be 52106-10.

Figure 1: All dots should be on the left side of the windings.

Figures 5, 6, and 9: Flow rates should be in SCCM.

Figures 7 and 8: Flow rates should be in SLM.

Figure BI: All dots on $L_{7}$ should be on left side of windings. 
End of Document 